\title{
Determining the quality of continuous casting from billet caster
}

\author{
Maria Androsenko ${ }^{1,}$, Ekaterina Kulikova ${ }^{1}$, Nail Tyuteryakov ${ }^{1}$, Elena Reshetnikova ${ }^{1}$, \\ Konstantin Pashenko ${ }^{1}$, and Alexey Yaroslavtsev ${ }^{1}$ \\ ${ }^{1}$ Nosov Magnitogorsk State Technical University, Lenin Avenue 38, Magnitogorsk, postcode 455000, \\ Russia
}

\begin{abstract}
There are various methods and practical examples to determine and to evaluate the production quality level. They include measuring, sensory, calculation, data-recording, sociological and expert methods. Among the variety of general-purpose statistical methods, only seven of them are chosen, which are applied by different specialists. They allow timely detecting and showing the problems, revealing the main points to start with, and helping to distribute the efforts to effectively fulfill main tasks.
\end{abstract}

\section{Introduction}

Various methods are used for concast ingot quality check, but the method of fuzzy sets together with expert method to estimate the quality of the concast ingot hasn't been previously applied to. Integral estimation of concast ingot quality has been developed. The factors that influence the quality - integral estimation $\left(\mathrm{I}^{\text {tr.int. }}\right)$ - have been determined in a four-phased approach by hierarchy analysis method and preference relation of fuzzy sets theory.

The factors that influence the product quality indicators are determined by means of fuzzy sets theory in conjunction with the survey and questioning of the personnel of MSP as well as scientists involved in this field. The analysis of the obtained data and an estimation of their degree of influence have been performed. The arithmetic average degree of importance of each factor is revealed, the membership function is developed. The integral quality estimation vector of the produced continuous casting ingot has been calculated. As a result of the calculations performed, it is possible to determine the vector of the factor influence on the quality of the concast ingot at each moment of operation. To test the results, one can use the simulation method.

The dependence of quality indicators of the billets on the values of identified factors is shown graphically.

According to the results of the analysis, it can be stated that while completing the order for a certain product possessing the specified quality parameters, the values of these parameters for all factors must correspond to the required level. And as a consequence, it is necessary to improve the quality of the production by adjusting the parameters of casting,

\footnotetext{
* Corresponding author: manechka.05@mail.ru
} 
level of unrequired inclusions and by improving the qualification of the personnel and the design of the secondary cooling zone.

To regulate the quality of any product manufactured it is necessary to determine the quality indicators and deviations from them caused by the influence of the various factors during manufacturing, storage, transportation, sale and usage of the production.

Various methods are used to determine and estimate the product quality indicators. They are: Measuring, sensory, computational, registrational, sociological and examining.

The wrong method can influence the accuracy and integrity of product quality estimation [1]. Methods to estimate the product quality are provided, regulated and classified by corresponding scientific and technical documentation according to GOST 15467-79.

Only seven methods out of many statistical ones are widely used. They include an affinity diagram, a tree diagram, a communication diagram, a matrix diagram, a decisionmaking process chart, a priority matrix and an arrow diagram [2].

To choose the method of data analysis it is necessary to take into account the following aspects: type to which each of the chosen objects belongs to: alternative (with or without the defect) or quantitative (for example: Sheet thickness.); actual control method currently applied; inspection period; change rate of object size; registration, integrity and completeness of the recorded information, its availability for the past periods. The control tool is chosen according to the type of the objects undergoing statistical control.

Different methods are used for quality analysis of the casted ingot but the method of fuzzy sets together with the examining methods have never been used for quality control of the casted ingot.

From the metallurgical point of view, it is difficult to estimate the quality of the casted ingot on the basis of all factors characterizing the controlled object from the quantitative and qualitative aspects. To consider all these factors convolution of separate indicators into a single one has been performed to give the integral estimation and reveal the influence degree of these factors on the quality. Account of different factors in a single estimation is possible due to mathematical statistics and fuzzy sets theory.

Mathematical theory of fuzzy sets allows to describe fuzzy data, to process them and to make corresponding conclusions [3]. It is proved that fuzzy control gives better results in comparison with the results obtained by conventional control algorithms.

These principles and approaches have been used in the development of an integral quality assessment of billet. The factors that influence the quality - integral assessment ( ${ }^{\text {tr.int }}$ ) - have been determined in four steps by hierarchy analysis method and preference relations of fuzzy sets theory

Initially the group of experts determined the most actual aspects and the degree of their importance for each factor that influences the quality of the billet.

The analysis of data obtained during the casting as well as analysis of the finished billet has been performed to estimate the whole complex of main factors that influence the quality of caster billet. The process personnel and the researchers from Magnitogorsk State Technical University competent in this sphere were asked to fill in the questionnaires. The obtained results were handled by the standard procedures of mathematical statistics (Fig. 1). 


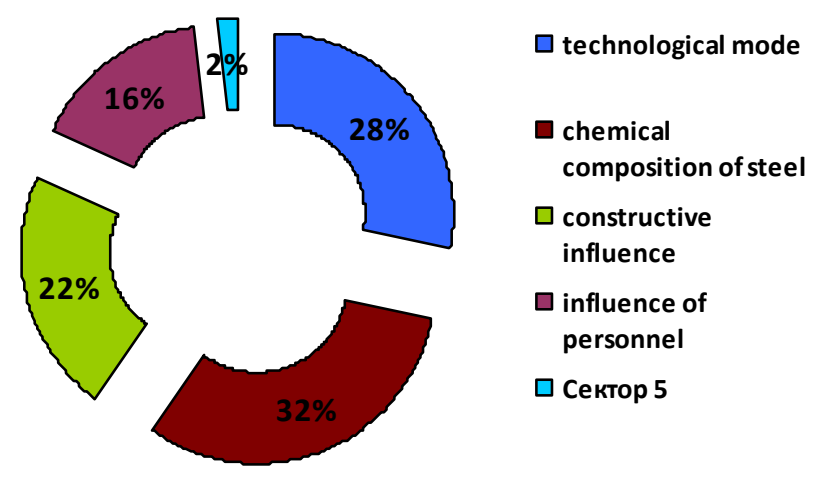

Fig. 1. Reasons for billet defects.

As a result, four groups of factors that influence the product quality have been established: chemical composition of steel, process mode, equipment design, human factor as well as other factors to which accidents can be referred to. Accidents are difficult to predict, and they are irregular. They depend on many random factors.

The chemical composition is characterized by inclusions of sulfur and phosphor which are the most harmful impurities in steel and alloys influencing the quality of the finished billet.

The process mode is objectively characterized by: method of casting; temperature; cooling mode.

The method of casting can be divided into an open jet and a closed jet casting. According to literature data and researches it is clear that closed jet casting reduces the harmful influence on the quality in comparison with the open jet casting.

Casting speed is always connected with the temperature of the casting steel. When the steel is overheated in the tundish ladle of the billet caster the possibility of the steel breakthrough increases. The reason for rhombic form is inhomogeneous primary cooling; uneven heat dissipation in the mold, insufficient or inhomogeneous secondary cooling.

Equipment design has the greatest effect on the quality: In the tundish ladle, in the mold and in a secondary cooling zone [11,12].

T-shaped tundish ladle without hydrodynamic device is used for the billet caster in MSP. To improve the quality, it is advisable to use a tundish [4] with a complex of partitions to form a stream in the casting chambers, to reduce the kinetic energy of the stream and to bring the jet down towards the surface slag.

The mold is supposed to be a copper mold; its wear rate is also taken into account (worn and new plates).

Secondary cooling zone can be with two or three rows of rollers. With the two-roller design of the secondary cooling zone breakthroughs are possible after the billet leaves the mold. It is due to a design deficiency of the secondary cooling unit caused by the large distance between the elements of the structure. As well as the design with three rows of rollers and an additional row of nozzles allows to reduce buckling and as a result the quality of the billet improves [5].

The influence of the personnel is examined at the level of: Managing personnel (age, education, work experience, level of professionalism) and working personnel (age, education, work experience, level of professionalism) [6].

The identified factors were structured into a hierarchical scheme and analyzed to define individual indicators that determine the strength of the influence of these factors. 
The assessment of the degree of influence of the identified factors was carried out by an expert method involving the working personnel of the casting bay of the billet caster of MSP MMK and competent researchers of FGBOU VPO MGTU named after G. I. Nosov.

As a result of the expert group survey the estimation of the degree of significance of this factor according to the scale of the degree of influence of factors was made for each factor: 1 - insignificant; 3 - weak; 5 - strong; 7 - very strong; 9 - absolute; 2,4,6,8 - intermediate values. The results of processing the questionnaires are presented in Figure 2.

Then it is necessary to determine the possible values of each factor and construct membership functions. The membership function sets the degree of preference for a particular value of a factor (the degree of preference is a real number in the range from 0 to 1) $[9-10]$.

\section{- assessment of degree of the importance of a factor}

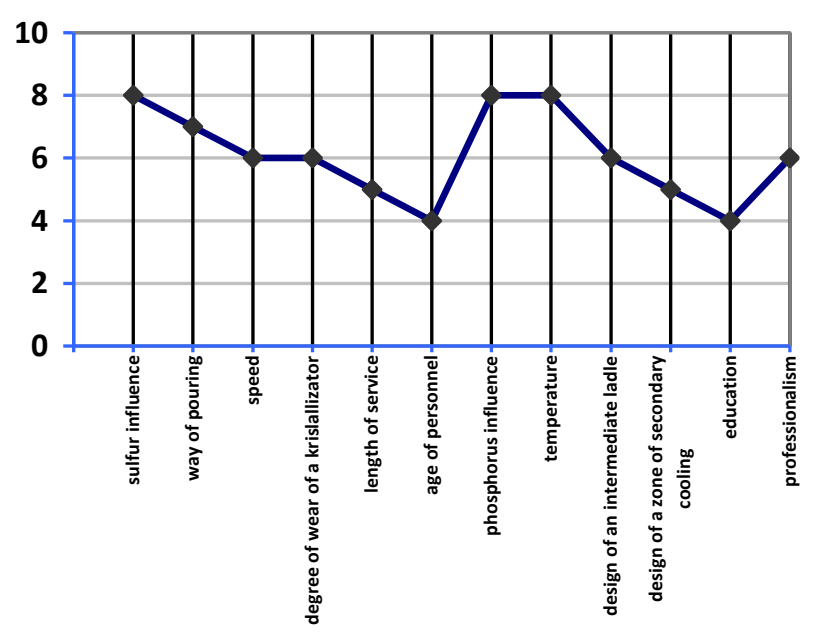

Fig. 2. Average Arithmetic Degree of Factor Value.

The construction of accessory functions is performed according to the principle of dependence of the quality level of the billet against the scale from 0 to 1 at an equal interval from the possible states of the factor. The group of experts gathered to construct the above mentioned functions. The method of statistical construction of membership functions has been chosen due to simplicity of usage and to the ability to consider all the individual features).

After constructing of the membership functions, a matrix of pairwise factor comparisons with the averaged results of expert assessments (the arithmetic mean of the significance of each factor) is created. The dimension of the matrix is $\mathrm{m}$ by $\mathrm{m}$, where $\mathrm{m}$ is the number of factors. The above mentioned matrix shows the significance of a particular factor in comparison with the other ones. Completion of pairwise comparison matrix can be performed by an expert or by a group of experts. Pairwise parameter comparison matrix is made for one time. This is a square and anti symmetrical matrix. The matrix is developed in Microsoft Excel. Then the normalized vector of the pairwise comparison matrix is calculated. The calculation of the vector is performed according to the formula of K. Pirson.

At the final stage, a matrix of values of all membership functions ( $\mathrm{n}$ by $\mathrm{m}$ ) of linguistic variables is developed, the matrix is presented in Table 1. The matrix of the actual values of membership function is corrected with regards to the normalized vector of pairwise 
comparison matrix. The resulting vector is the integral estimation of the produced concast billet quality.

Calculation of the vector of the integral quality evaluation of the produced concast billet is performed according to the following formula:

$$
\vec{I}^{\text {MpH }}=a \cdot \vec{N}^{\text {MpME }}
$$

where $a_{i j}-$ is the matrix of values of all membership functions of linguistic variables; $\vec{N}^{m p}$ - normalized vector of the matrix of pairwise comparisons.

Matrix consistency is checked by calculating the consistency index and the consistency relation [7].

As a result of the calculations performed for every work moment, it is possible to determine the vector of influence of factors on the quality of a continuously cast billet. To verify the obtained results, it is possible to use the simulation method.

Table 1. Matrix of the membership function values for the quality indicators of the billet (steel grade St3sp).

\begin{tabular}{|c|c|c|c|c|c|c|c|c|c|c|c|c|c|c|}
\hline & $\begin{array}{l}\frac{\infty}{\delta} \\
\text { ஸे } \\
\text { ô. } \\
\infty \\
\infty\end{array}$ & 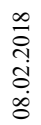 & $\begin{array}{l}\stackrel{\infty}{\circ} \\
\text { } \\
\text { ¿ิ } \\
\stackrel{0}{0}\end{array}$ & 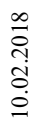 & 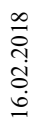 & 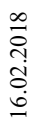 & 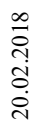 & 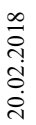 & 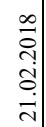 & 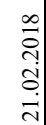 & 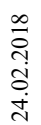 & 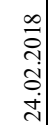 & & \\
\hline Sulphur content & 0.8 & 1 & 0.8 & 0.8 & 0.6 & 0.6 & 0.8 & 0.8 & 0.6 & 0.8 & 0.8 & 0.8 & & \\
\hline phosphorous content & 1 & 1 & 0.8 & 0.8 & 0.8 & 0.8 & 0.8 & 0.8 & 0.6 & 0.8 & 0.8 & 0.8 & & \\
\hline way of pouring became & 1 & 1 & 1 & 1 & 0.7 & 0.7 & 0.7 & 0.7 & 0.7 & 0.7 & 1 & 1 & & \\
\hline $\begin{array}{c}\text { temperature in an } \\
\text { intermediate ladle } \\
\end{array}$ & 1 & 1 & 1 & 1 & 0.8 & 0.8 & 0.8 & 0.8 & 0.7 & 1 & 1 & 0.8 & & \\
\hline speed of pouring became & 1.0 & 1.0 & 0.6 & 0.6 & 0.8 & 0.8 & 0.8 & 0.8 & 0.6 & 1.0 & 0.6 & 0.6 & & \\
\hline \begin{tabular}{|l|} 
construction of an \\
intermediate ladle
\end{tabular} & 1 & 1 & 1 & 1 & 1 & 1 & 1 & 1 & 0.6 & 1 & 1 & 1 & & \\
\hline wear of crystallizer & 1 & 1 & 1 & 1 & 1 & 1 & 1 & 1 & 0.7 & 1 & 1 & 1 & & \\
\hline $\begin{array}{l}\text { design of a zone of } \\
\text { secondary cooling }\end{array}$ & 1 & 1 & 1 & 0.8 & 0.6 & 0.6 & 1 & 0.6 & 1 & 0.8 & 1 & 1 & & \\
\hline age & 1 & 1 & 0.9 & 0.9 & 0.6 & 0.6 & 0.8 & 0.8 & 0.4 & 1 & 0.9 & 0.9 & & \\
\hline education & 0.8 & 0.8 & 0.8 & 0.8 & 0.6 & 0.6 & 0.8 & 0.8 & 0.4 & 0.6 & 1 & 1 & & \\
\hline working experience & 0.9 & 0.9 & 1 & 1 & 0.7 & 0.7 & 0.9 & 0.9 & 0.6 & 1 & 1 & 1 & & \\
\hline professionalism & 1 & 1 & 1 & 1 & 0.8 & 0.8 & 1 & 1 & 0.6 & 1 & 1 & 1 & & \\
\hline the normalized vector & $\begin{array}{l}{ }_{0}^{\circ} \\
0 \\
0\end{array}$ & $\begin{array}{l}8 \\
0 \\
0 \\
0\end{array}$ & $\begin{array}{l}\frac{n}{\infty} \\
\frac{\infty}{0} \\
0\end{array}$ & 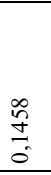 & $\stackrel{2}{3}$ & $\stackrel{2}{3}$ & $\frac{10}{9}$ & $\begin{array}{l}\text { ? } \\
\text { on } \\
0\end{array}$ & 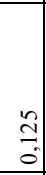 & $\begin{array}{l}\text { â } \\
0 \\
0\end{array}$ & $\begin{array}{l}3 \\
\infty \\
0 \\
0 \\
0\end{array}$ & 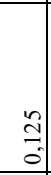 & - & $\begin{array}{l}\text { 导 } \\
\stackrel{0}{0} \\
0\end{array}$ \\
\hline intermediate value & $\begin{array}{c}\text { ले } \\
\stackrel{2}{-}\end{array}$ & $\because$ & $\frac{\mathfrak{2}}{2}$ & $\begin{array}{l}n \\
\infty \\
\infty \\
0\end{array}$ & $\begin{array}{l}\text { In } \\
0\end{array}$ & 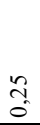 & $\begin{array}{l}\text { के } \\
\infty \\
n \\
0\end{array}$ & 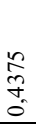 & $\overrightarrow{0}$ & $\begin{array}{l}2 \\
0 \\
0 \\
0\end{array}$ & $\begin{array}{l}8 \\
: \\
0 \\
0 \\
0\end{array}$ & - & 이 & ๙2 \\
\hline $\begin{array}{l}\text { Assessment of quality } \\
\text { of melting became }\end{array}$ & \begin{tabular}{l}
\multirow{2}{2}{} \\
$\stackrel{\Im}{ \pm}$ \\
$\stackrel{0}{0}$
\end{tabular} & $\begin{array}{l}\overrightarrow{\hat{\imath}} \\
0 \\
0 \\
0\end{array}$ & $\begin{array}{l}\text { İ } \\
\text { ठे } \\
\text { t } \\
0\end{array}$ & 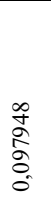 & 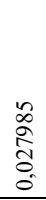 & 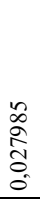 & 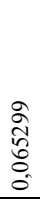 & 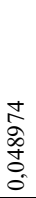 & $\begin{array}{l} \pm \\
\Xi \\
\Xi \\
0 \\
0\end{array}$ & $\begin{array}{l}\Re \\
\vdots \\
0 \\
0 \\
0\end{array}$ & \begin{tabular}{l}
$\widehat{\hat{N}}$ \\
+ \\
\multirow{0}{0}{} \\
0
\end{tabular} & $\begin{array}{l} \pm \\
2 \\
\Xi \\
\overrightarrow{0}\end{array}$ & - & - \\
\hline
\end{tabular}


According to the results of the researches, the graphs [8] have been made for the particular period of time with the billet optimal quality indicator depending on the degree of factor significance. The graphs help to judge on the product quality for a particular period of time.
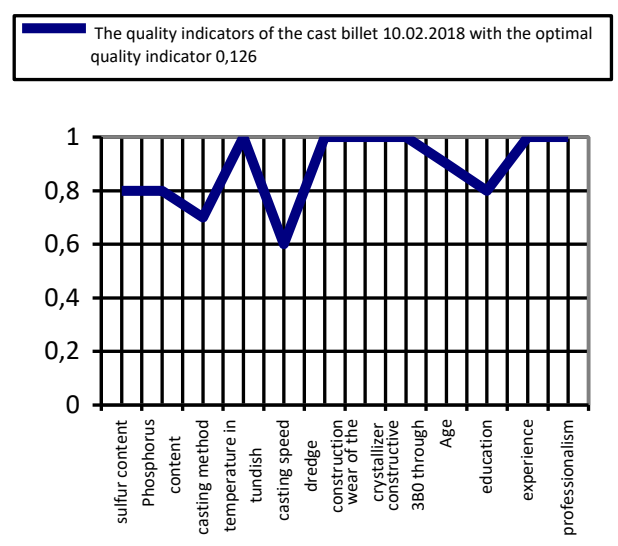
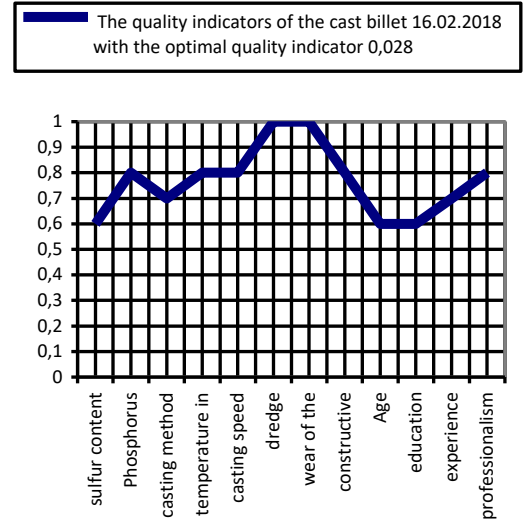
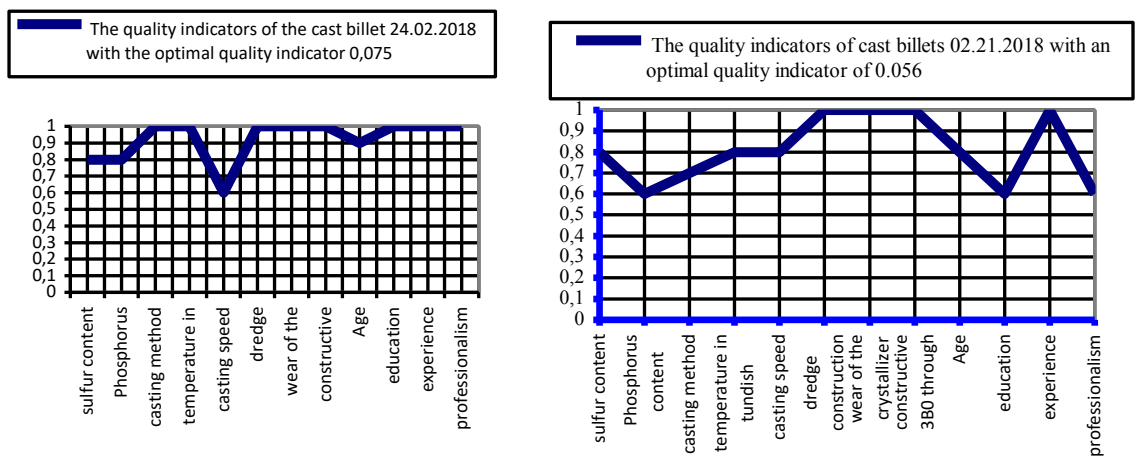

Fig. 3. Effect of the optimal quality indicator depending on the degree of preference for the particular period of time.

After analyzing all of the above we can conclude that when executing an order for a certain product with given quality indicators of the billet, the values of the parameters are to correspond to the required level for all factors. Consequently, it is important to increase the quality by adjusting the parameters of casting and impurities, improve professionalism of the personnel and design of the secondary cooling zone.

\section{References}

1. M.V. Androsenko, V.I. Kadoshnikov, D.A. Harlov, Engineering: Past, Present, Future: a collection of articles of the International scientific-practical conference, 63-65 (2014)

2. A.N. Pavlov, B.V. Sokolov, Decision-making in the conditions of indistinct information (FGOU VPO publishing house of St. Petersburg State University of Aerospace Instrumentation, St. Petersburg, 2006)

3. A.I. Orlov, Non-numerical statistics (MZ-Press, Moscow, 2004) 
4. M.V. Androsenko, Eastern European Scientific Journal. AURIS Kommunikations- und VerlagsgesellschaftmbH (2014) DOI 10.12851 / EESJ201406

5. V.I. Kadoshnikov, I.M. Zakharov, A.B. Great, S.Yu. Zaytsev, M.V. Aksenova, A.P. Batrashkin, The device for maintenance of an ingot in a zone of secondary cooling of MNLZ: Stalemate. The Russian Federation on useful model No. 105849 (Magnitogorsk Iron and Steel Works, Magnitogorsk, 2011)

6. M.V. Aksenov, N.A. Kvasova, Scientific and Technical Gazette Volga 4, 94-98 (2013)

7. N.B. Haptahaeva, S.V. Dambaeva, N.N. Ayusheeva, Introduction to the theory of fuzzy sets (Izd ESSTU, Ulan-Ude, 2004)

8. M.V. Androsenko, I.D. Kadoshnikova, Heavy engineering industry 9, 30-33 (2015)

9. A.D. Sirazetdinova, Methods of control traffic volumes on the roads uncom-mon, taking into account the operational load stations (Magnitogorsk 2010)

10. L.P. Demidov, The development of methods to support the tasks of the theory of fuzzy sets and genetic algorithms, decision making under uncertainty (Ryazan, 2009)

11. S.A. Botnikov, Influence of chemical composition and technology of refining low carbon and medium carbon steel casting parameters on the "MMK", dis. cand. tehn. sciences (Chelyabinsk, 2009)

12. A.M. Stolyarov, A.B. Great, D.V. Yurechko, Improving the efficiency of casting steel high-koproizvoditelnyh "MMK", monograph (GOU VPO "MagnitogorskState Technical Uni-versity", Magnitogorsk, 2009) 